\title{
Effect of Initial Temperature on Iron Nugget Formation in Fluxless Processing of Titanomagnetite Under Isothermal - Temperature Gradient Profiles
}

\author{
Zulfiadi Zulhan ( $\nabla$ zulfiadi.zulhan@gmail.com ) \\ Bandung Institute of Technology \\ Cheryl Livia Sutandar \\ Bandung Institute of Technology \\ Indah Suryani \\ Bandung Institute of Technology \\ Eddy Agus Basuki \\ Bandung Institute of Technology
}

\section{Research Article}

Keywords: titanomagnetite, iron nugget, fluxless, carbothermic, temperature profile

Posted Date: October 28th, 2021

DOI: https://doi.org/10.21203/rs.3.rs-1010950/v1

License: (c) (i) This work is licensed under a Creative Commons Attribution 4.0 International License.

Read Full License 


\section{Abstract}

Recently, the titanomagnetite by coal producing iron nugget under isothermal - temperature gradient profile is introduced. The reduction process is divided into three stages where in the first stage the initial temperature is kept constant for a certain of time and then the temperature is increased to $1380^{\circ} \mathrm{C}$ with a certain heating rate in the second stage and finally in the third stage the temperature is maintained at $1380^{\circ} \mathrm{C}$ for a certain time. The results of the experiments show that the initial temperature in the first stage affects the formation of iron nuggets. Initial temperatures of 700 to $1100^{\circ} \mathrm{C}$ produce many nuggets up to $3 \mathrm{~mm}$ in size, initial temperature of $1200^{\circ} \mathrm{C}$ produces one nugget with a size of about $4 \mathrm{~mm}$ and the initial temperatures of 1300 and $1380^{\circ} \mathrm{C}$ do not produce nuggets. Optimal iron recovery is achieved at an initial temperature of $1000^{\circ} \mathrm{C}$. The slag contains titanium oxide, armalcolite and rest of metallic iron with a size of less than $0.5 \mathrm{~mm}$. The nugget formation is believed due to the aggregation and agglomeration of iron particle during the increasing temperature from initial stage to $1380^{\circ} \mathrm{C}$.

\section{Introduction}

Titanomagnetite (TTM) is one of the raw materials for the production of iron, titania and vanadium. Indonesia is one of the countries that has titanomagnetite resources, mainly from the iron sand on the beach, in the amount of 941 million tons. The technology that can be used to process ISC is currently limited to rotary kilns - electric furnaces. ${ }^{[1,2]}$ It is necessary to add limestone to adjust the chemical composition of the slag for the smelting stage in the electric furnace which has a negative impact on reducing the titania content in the slag. Fluxless smelting of ISC or TTM in electric furnace was suggested to increase the titania content in the slag. ${ }^{[3]}$

In addition, blast furnaces can be used but the ISC must be mixed with ordinary iron ore where the maximum amount of ISC is about $65 \%$ in the mixture. ${ }^{[4,5]}$ Due to the lower operating temperature of the blast furnaces than the electric furnaces, it is necessary to add more fluxes which can dilute the titania content in the slag. In addition, the other problems are the formation of $\mathrm{TiC}$ and $\mathrm{TiN}$ because the atmosphere in the hearth blast furnace is very reductive and the use of hot blast air in the tuyeres as a nitrogen source. TiC and TiN cause the slag to become viscous and the separation between hot metal and slag becomes constrained which causes a lot of metal to be trapped and enter the slag. ${ }^{[6]}$

Alternatively, many studies have focused on direct reduction in the solid state of TTM by carbonaceous materials wherein iron can be separated from other oxides using magnetic separators. ${ }^{[7-23]}$ Coal as reducing agent had shown better performance than coke, graphite or biochar. ${ }^{[22]}$ The addition of coal can be done simultaneously through mixing with TTM or also by immersing pellets or briquettes into the coal bed or coal embedding. The optimum temperature for the TTM reduction was $1200^{\circ} \mathrm{C} .{ }^{[17,21]}$ The addition of sodium sulfate, sodium carbonate and calcium fluorite as additives was also investigated to promote the migration, accumulation, and growth of iron into larger particles. ${ }^{[10,13,16,18,23]}$ The nugget formation 
with a treatment time of 440 min and temperatures up to $1350^{\circ} \mathrm{C}$ was observed by Hu et al. ${ }^{[8]}$, but in experiments using a laboratory scale rotary hearth furnace at a temperature of $900-1350^{\circ} \mathrm{C}$ which was divided into three zones, no nuggets formation was reported ${ }^{[12]}$.

In previous work we have introduced that iron nuggets were formed by carbothermic reduction of ISC under an isothermal-temperature gradient profile starting from the initial temperature at $1000^{\circ} \mathrm{C}$ and increasing to a final temperature of $1380^{\circ} \mathrm{C}$ at a heating rate of $6.33^{\circ} \mathrm{C} / \mathrm{min}$ with a total reduction time of less than $150 \mathrm{~min} .{ }^{[24]}$ The initial temperature may influence the iron recovery in the nuggets. Therefore, in paper, we report the effect of initial temperature on the iron nugget formation and the recovery of iron in nuggets.

\section{Methods}

Titanomagnetite was taken from one of mining and beneficiation plants situated in Sukabumi, West Java, Indonesia. To remove the moisture content, the ISC was dried in an oven for $24 \mathrm{~h}$ at $130^{\circ} \mathrm{C}$. The grain size of the ISC was less than $0.212 \mathrm{~mm} \mathrm{(-65 \# )} \mathrm{and} \mathrm{the} \mathrm{details} \mathrm{of} \mathrm{the} \mathrm{grain} \mathrm{size} \mathrm{distribution} \mathrm{are} \mathrm{given}$ in Table 1. The chemical composition was determined by X-ray fluorescence (XRF) as listed in Table 2 wherein the iron content was $55.35 \%$ and titanium $6.70 \%$. The main minerals in the ISC as determined by X-ray diffraction (XRD) were titanomagnetite $\left(\mathrm{Fe}_{2.75} \mathrm{Ti}_{0.25} \mathrm{O}_{4}\right)$ and magnetite $\left(\mathrm{Fe}_{3} \mathrm{O}_{4}\right)$ with traces of ilmenite $\left(\mathrm{FeTiO}_{3}\right)$. Similar minerals were reported by other researchers who used Indonesian ISC as experimental material. ${ }^{[13,14,18]}$ Coal reducing agent was prepared using a roll crusher, and a ball mill to obtain a grain size of less than $35 \#(-0.425 \mathrm{~mm})$. The coal was dried in an oven for $24 \mathrm{~h}$ at $130^{\circ} \mathrm{C}$ to remove its moisture content. The proximate and ultimate analyses of coal are listed in Table 3 and 4 , respectively.

Table 1

Grain size distribution of titanomagnetite (wt\%).

\begin{tabular}{|lllll|}
\hline$-325 \#$ & $-200 \#+325 \#$ & $-170 \#+200 \#$ & $-80 \#+170 \#$ & $+80 \#$ \\
$(-0.044 \mathrm{~mm})$ & $(0.044-0.074 \mathrm{~mm})$ & $(0.074-0.088 \mathrm{~mm})$ & $(0.088-0.177 \mathrm{~mm})$ & $(+0.177 \mathrm{~mm})$ \\
\hline 9.11 & 23.31 & 9.12 & 34.97 & 23.49 \\
\hline
\end{tabular}

Table 2

Chemical composition of titanomagnetite (wt\%).

\begin{tabular}{|llllllll|}
\hline $\mathbf{F e}$ & $\mathbf{T i}$ & $\mathbf{A l}$ & $\mathbf{M g}$ & $\mathbf{S i}$ & $\mathbf{M n}$ & $\mathbf{P}$ & $\mathbf{S}$ \\
\hline 55.35 & 6.70 & 1.88 & 1.12 & 1.32 & 0.39 & 0.033 & 0.005 \\
\hline
\end{tabular}


Table 3

Proximate analysis of coal (wt\%, adb) a).

\begin{tabular}{|llll|}
\hline Inherent moisture & Volatile matter & Ash & Fixed carbon \\
\hline 4.31 & 38.10 & 15.31 & 42.28 \\
\hline a) $\mathrm{adb}$ = air dried basis & & \\
\hline
\end{tabular}

Table 4

\begin{tabular}{|l}
\begin{tabular}{|lllll|}
\hline Ultimate analysis of coal $(\mathrm{wt} \%, \mathrm{adb}){ }^{\mathrm{a}}$. \\
\hline $\mathbf{C}$ & $\mathbf{H}$ & $\mathbf{N}$ & $\mathbf{0}$ & $\mathbf{S}$ \\
\hline 62.54 & 5.31 & 1.16 & 14.74 & 0.94 \\
\hline
\end{tabular}
\end{tabular}

The ISC was mixed with $20 \mathrm{wt} \%$ coal where the weight of ISC was used as the basis. Four grams of the mixture was formed into cylindrical briquettes using a $15 \mathrm{~mm}$ diameter die with the help of a hydraulic press. The briquette thickness was about $9 \mathrm{~mm}$. Before a briquette was loaded into a 20-mL alumina crucible equipped with a lid, a layer of coal was prepared at the bottom of the crucible. After the briquette was loaded in the crucible, more coal was added in the crucible to maintain the reducing environment and support the reduction by covering the entire surface of the briquette. The total addition of coal for this purpose was $5 \mathrm{~g}$. The addition of coal was a combination of self-reducing briquette and briquette embedded in coal.

The experiments were carried out in a muffle furnace without controlling the atmosphere and under the isothermal-temperature gradient profile in the furnace. The temperature referred to here was the furnace temperature. Three briquettes were prepared and reduced for each experimental parameter to obtain reliable results. After the experiment, the crucibles were removed from the muffle furnace, and the reduced briquettes were cooled to room temperature in the crucible. Then, the reduced briquettes were weighed, documented, and examined by scanning electron microscopy (SEM) and energy dispersive X-ray spectroscopy (EDS). The iron nuggets formed in the reduced briquettes were separated from the slag manually by hand sorting with the help of tweezers. The nuggets and slag were weighed, and the size of the nuggets was measured by a caliper. The bisection of the nuggets was examined by optical microscopy and SEM-EDS. The slag was analyzed by XRD.

\section{Results And Discussion}

\subsection{Temperature Pattern and Physical Appearance of Reduced Briquette}

As previously reported, iron nuggets were formed by reducing of ISC/coal composite pellets under an isothermal-temperature gradient profile where the initial temperature was $1000^{\circ} \mathrm{C}$ and the final temperature was $1380^{\circ} \mathrm{C} .^{[24]} \mathrm{An}$ initial temperature of $1000^{\circ} \mathrm{C}$ was chosen based on the results of 
previous experiments on the reduction of titanomagnetite by coal which showed that metallic iron was formed at temperatures higher than $900^{\circ} \mathrm{C} .^{[22]}$ Other initial temperatures may have an influence on nugget formation. Therefore, the initial temperature was varied as shown in Figure 1. Pattern A was started by setting the furnace temperature at $700^{\circ} \mathrm{C}$ and held for $40 \mathrm{~min}$ at $700^{\circ} \mathrm{C}$, then the furnace temperature was increased to $1380^{\circ} \mathrm{C}$ in $68 \mathrm{~min}$ with a heating rate of $10^{\circ} \mathrm{C} / \mathrm{min}$ and finally held at $1380^{\circ} \mathrm{C}$ for $22 \mathrm{~min}$. The total treatment time was $130 \mathrm{~min}$. The same procedure was carried out on the other temperature patterns until the $\mathrm{H}$ pattern where the temperature was constant from start to the end at $1380^{\circ} \mathrm{C}$. For information, the temperature intended and set in the experiments was the furnace temperature, not the temperature at the surface of the briquette with coal in alumina crucible.

Figure 2 shows the physical appearance of the reduced briquettes. The temperature pattern $A$ to $E$ formed iron nuggets in large numbers but with similar and smaller sizes. The $\mathrm{F}$ temperature pattern produced fewer nuggets, but they are larger in size. No nuggets were formed on reduced briquettes using the temperature patterns $\mathrm{G}$ and $\mathrm{H}$. From the observation of this physical appearance, it can be concluded that the initial temperature of ISC/coal composite briquettes reduction under an isothermal-temperature gradient profile played a very important role in the formation of iron nuggets on the surface of reduced briquettes.

\subsection{Nugget size and iron recovery in Nugget}

The reduced briquettes were crushed using a mortar and the iron nuggets were separated from the slag as shown in Figure 3. The results of the measurement of the nugget size are shown in Figure 4a as a function of temperature pattern from two reduced briquettes for each experimental parameter. The temperature patterns $\mathrm{G}$ and $\mathrm{H}$ were not plotted in the graph because no nuggets were visible on the surface of reduced briquettes. The number of nuggets is also shown in the Figure $4 \mathrm{a}$. It can be seen that the maximum nugget size of about $4 \mathrm{~mm}$ can be achieved using the $\mathrm{F}$ temperature pattern. In addition, it is also seen that only one large nugget was produced using the $F$ temperature pattern. In the $A$ to $D$ temperature pattern, the average size of the nuggets was about $1 \mathrm{~mm}$ with a maximum size ranging from 2.2 to $2.7 \mathrm{~mm}$. Approximately 90 nuggets were separated from each reduced briquette using $A$ to $D$ temperature pattern. These nuggets are larger than $0.3 \mathrm{~mm}$. Nuggets smaller than $0.3 \mathrm{~mm}$ remained in the slag which can be further recovered by using for example a magnetic separator. The temperature pattern $E$ showed a maximum nugget size of $3 \mathrm{~mm}$ with an average size of $1.3 \mathrm{~mm}$. The size of nugget from pattern $E$ was between the sizes of nuggets produced from temperature patterns $D$ and $F$. The number of nuggets from one reduced briquette using temperature pattern $E$ was 44 . Details of the size distribution of nugget resulting from each temperature pattern are shown in Figure $4 \mathrm{~b}$.

The weight of the reduced briquettes, slag and iron nuggets is shown in Figure 5a. Based on these data, the iron recovery in the nuggets was calculated where the results are depicted in Figure 5b. It can be seen that iron recovery in nuggets increased from temperature pattern A with initial temperature of $700^{\circ} \mathrm{C}$ and achieved optimum iron recovery in temperature pattern $D$ with initial temperature of $1000^{\circ} \mathrm{C}$. Subsequently, the iron recovery decreased as shown in temperature patterns $\mathrm{E}$ dan $\mathrm{F}$ with initial temperatures of $1100^{\circ} \mathrm{C}$ and $1200^{\circ} \mathrm{C}$, respectively. 
As previously reported ${ }^{[22]}$ for solid-state reduction of ISC under isothermal conditions, at 700 or $800^{\circ} \mathrm{C}$, a certain amount of magnetite in titanomagnetite was reduced to wustite but no metallic iron was formed. Although no metallic iron was formed at 700 or $800^{\circ} \mathrm{C}$ in the first initial stages of temperature patterns $\mathrm{A}$ and $\mathrm{B}$, further reduction of the iron oxides in the briquettes occurred in the second stage, where heating was carried out from 700 or $800^{\circ} \mathrm{C}$ to $1380^{\circ} \mathrm{C}$ resulting in iron nuggets as shown clearly on the surface of the reduced briquettes in Figures $2 \mathrm{a}$ and $2 \mathrm{~b}$. The iron recovery in the nuggets for temperature patterns $\mathrm{A}$ and $B$ was similar at about $43 \%$ (Figure $5 b$ ).

As the initial temperature increased to $900^{\circ} \mathrm{C}$, metallic iron was formed with a metallization degree of about $13 \%{ }^{[22]}$ attainable during the first isothermal step for duration of $40 \mathrm{~min}$. Therefore, the iron recovery in nuggets increased from $43 \%$ (temperature pattern $\mathrm{B}$ ) to $50 \%$ (temperature pattern $\mathrm{C}$ ). At $1000^{\circ} \mathrm{C}$, the metallization degree increased to about $30 \%{ }^{[22]}$ during the isothermal step so that the recovery increased to $53 \%$ for the nuggets resulting from the temperature pattern $D$. Temperature pattern D with an initial temperature of $1000^{\circ} \mathrm{C}$ seems to be the optimum temperature pattern for achieving high iron recovery in the form of nuggets.

Further increase in initial temperature tended to reduce the iron recovery in the nuggets as well as the nugget formation. At an initial temperature of $1100^{\circ} \mathrm{C}$, the metallization degree increased to about $50 \%$ [22] at the first isothermal step for $40 \mathrm{~min}$, but the iron recovery in the nuggets decreased. This can be caused by the formation of large amounts of metallic iron on the surface of the briquette at the first stage of isothermal which can inhibited the migration of metal from the center to the outer surface of the briquette. The results of previous study indicated that the important step for nugget formation was the second stage on the isothermal - temperature gradient profile where the temperature was increased with a certain heating rate towards $1380^{\circ} \mathrm{C}$.

Further increasing the initial temperature to $1200^{\circ} \mathrm{C}$ reduced the porosity on the briquette surface in addition to increasing the metallization degree so that the formation of nuggets became more difficult. At initial temperatures of $1300^{\circ} \mathrm{C}$ and $1380^{\circ} \mathrm{C}$, no nugget was formed although the metallization degree throughout the briquettes increased. Besides the initial temperature, the heating rate can also affect the formation of iron nuggets.

Geng et al. ${ }^{[17]}$ investigated the reduction of ISC pellets by embedding in coal as a reducing agent under isothermal conditions in the temperature range of 1100 to $1300^{\circ} \mathrm{C}$. The reduced pellets were crushed and ground to less than $0.043 \mathrm{~mm}$ and the metallic iron was recovered by magnetic separator technique. It was reported that the optimum temperature was $1200^{\circ} \mathrm{C}$ to achieve high iron recovery and high iron grade. In the temperature range of 1250 to $1300^{\circ} \mathrm{C}$, the semi molten phase was formed which prevented the reducing gas from the embedded coal entering the center of pellet ${ }^{[17,21]}$.

As mentioned earlier, the nuggets which were recovered have the size of larger than $0.3 \mathrm{~mm}$. The nuggets that were less than $0.3 \mathrm{~mm}$ in size cannot be recovered by hand sorting where the other techniques muss be applied. The slag was analyzed by XRD where the results are shown in Figure 6 for temperature 
patterns $A, D$ and $F$. It can be seen that the metallic iron was still dominant in the slag. Titanium was presented as titanium oxide (TiO) and armalcolite $\left(\left(\mathrm{Mg}_{0.5} \mathrm{Fe}_{0.5}\right) \mathrm{Ti}_{2} \mathrm{O}_{5}\right)$.

The Indonesian ISC was used as experimental material by previous researchers. Gao et al. ${ }^{[13]}$ reported that the phases in an ISC mixture with $25 \%$ coal reduced at $1250^{\circ} \mathrm{C}$ were metallic iron, ilmenite, and armalcolite. A similar experiment was carried out by Geng et al. ${ }^{[13]}$ and found that the phases in pellets reduced by embedding in the coal were metallic iron, ilmenite and pseudobrookite $\left(\mathrm{FeTi}_{2} \mathrm{O}_{5}\right)$. Recently, Zhao et al. ${ }^{[21,23]}$ reported that the phases in the reduced mixture consisting of ISC and $25 \%$ coal at 1200 $1300^{\circ} \mathrm{C}$ were metallic iron, ilmenite, and anosovite $\left((\mathrm{Fe}, \mathrm{Mg}) \mathrm{Ti}_{2} \mathrm{O}_{5}\right)$. From the experiments mentioned above, the iron nuggets were not formed, the metallic iron was still attached to other oxides. Therefore, a series of crushing and grinding treatments are required to liberate the metallic iron.

\subsection{Microstructure and SEM-EDS Observation}

The surface of briquette that was reduced under temperature pattern A was analyzed by SEM-EDS as shown in Figure 7. Many nuggets with a size of less than $20 \mu \mathrm{m}$, called micro nuggets, were visible on the surface of briquette. These micro nuggets have not been agglomerated to form larger nuggets. These micro nuggets were impossible to separate from the slag by hand sorting and remained in the slag as shown by XRD pattern in Figure 6 where the metallic iron was the dominant phase. Other separation technique is required, e.g., a magnetic separator to recover these micro nuggets. In addition, a nugget with a size of $0.33 \mathrm{~mm}$ was clearly visible on the surface of briquette. This nugget size may still be difficult to separate from the slag manually by hand sorting as shown in Figure 4a for the minimum size of the nuggets that was counted for iron recovery. On the surface of this nugget, "flower"-like motifs with light gray color revealed. Inside this nugget, the shape like micro nuggets can be seen clearly where the micro nuggets were covered by a transparent layer. A similar phenomenon was observed in other nuggets as shown in Figure 8 where the agglomerated micro nuggets were covered by a transparent layer forming a large nugget size.

SEM-EDS analysis on the surface of nuggets which were produced from temperature pattern $A, D$ and $F$ are shown in Figure 9. From Figure 9a, it is clear that the formation of "flower"-like motifs on the surface of nuggets in Figure 7 was caused by the presence of manganese together with sulphur, and iron form a sulphide phase which had a lower melting point. Manganese came from ISC as listed in Table 2 and sulfur from coal as the sulfur content in the ISC is very low $(0.005 \%)$. The combination of iron, manganese and sulfur may form FeS.2MnS with has a melting point of $1128^{\circ} \mathrm{C}$ that solidified last on the surface of nuggets. The other phases are oxides containing aluminum, magnesium, and iron. Figure $9 \mathrm{~b}$ and $9 \mathrm{c}$ show the oxides were formed on the surface of nugget containing iron, titanium, aluminum, and oxygen.

The microstructure images from optical microscopy of the bisection of nuggets resulting from temperature patterns A, D and $F$ are shown in Figure 11a - 11c while of the polished surface of reduced briquette is shown in Figure 11d. Grain boundaries are clearly visible in Figure 11a with a magnification 
of 200 - which may be formed from the agglomeration of small metal particles with one another. It was believed that the metal was not completely melted, the metal phase was semi liquid. During agglomeration, the unreduced oxides were trapped between one metal particle and another. Grain boundaries and trapped oxides as well as sulfide precipitations at the grain boundaries can be seen clearly in Figure 11c. Figure 11d shows metallic iron formed on the surface of the reduced briquettes. To recover the metallic iron with a magnetic separator, a comminution step consisting of crushing and grinding is required to liberate the metallic iron particles from the unreduced oxides. This technique was reported by pervious researchers. ${ }^{[13,17,21,23]}$

\section{Conclusion}

The effect of initial temperature on the formation of iron nuggets under isothermal - gradient temperature profile where a final temperature of $1380^{\circ} \mathrm{C}$ was investigated. Initial temperatures of 700 to $1100^{\circ} \mathrm{C}$ produce many nuggets up to $3 \mathrm{~mm}$ in size, initial temperature of $1200^{\circ} \mathrm{C}$ produces one nugget with a size of about $4 \mathrm{~mm}$ and the initial temperatures of 1300 and $1380^{\circ} \mathrm{C}$ do not produce nuggets. The optimum initial temperature was $1000^{\circ} \mathrm{C}$ to achieve high iron recovery in the nuggets. The nuggets were formed by the agglomeration of micro nuggets or metal particles which were reduced at temperature of more than $900^{\circ} \mathrm{C}$. The agglomeration is believed to occur during the heating stage from initial temperature to $1380^{\circ} \mathrm{C}$ with a certain heating rate.

\section{Declarations}

\section{Acknowledgements}

The authors would like to thank the Ministry of Research, Technology, and Higher Education of the Republic of Indonesia for funding this research and PT. Sumber Baja Prima, Indonesia, for providing the titanomagnetite concentrate.

\section{Competing interests}

The authors declare no competing interests.

\section{Author contributions}

Z. Z.: Conceptualization, Methodology, Formal analysis, Validation, Funding acquisition, Project administration, Writing - review \& editing. C. L. S.: Methodology, Investigation, Formal analysis, Validation, Writing - original draft, I. S.: Conceptualization, Methodology, Formal analysis. E. A. B.: Conceptualization, Formal analysis, Validation, Funding acquisition, Writing - review \& editing. All authors have read and agreed to the published version of the manuscript.

\section{Competing interests}

The authors declare no competing interests. 


\section{Data Availability}

All data generated or analysed during this study are included in this published article.

\section{References}

1. Ure, C. R. Alternative ironmaking at BHP New Zealand Steel. Proc. 2000 Electric Furnace Conference, AIST, Warrendale, USA, 535-546(2000).

2. Steinberg, W. S., Geyser, W. \& Nell, J. The history and development of the pyrometallurgical processes at Evraz Highveld Steel \& Vanadium. J. South. Afr. Inst. Min. Metall, 111, 705-710 (2011).

3. Geldenhuys, I. J., Akdogan, G. \& Reynolds, Q. G. Towards sustainable processing of vanadiumbearing titaniferous magnetite deposits - an overview of barriers and opportunities. IMPC 2020, Cape Town, South Africa, 2566-2581(2020).

4. Pang, Z., Lv, X., Jiang, Y., Ling, J. \& Yan, Z. Blast Furnace Ironmaking Process with Super-High TiO2 in the Slag: Viscosity and Melting Properties of the Slag. Metal. Mater. Trans. B, 51B, 722-731 (2020).

5. Fu, W. G. \& Xie, H. E. Progress in Technologies of vanadium-bearing titanomagnetite smelting in PanGang. Steel Res. Int, 82, 501-504 (2011).

6. Wang, S. et al. Reduction Behaviors of Iron, Vanadium and Titanium Oxides in Smelting of Vanadium Titanomagnetite Metallized Pellets. JOM, 69, 1646-1653 (2017).

7. Chen, D. et al. Solid state reduction of Panzhihua titanomagnetite concentrates with pulverized coal. Min. Eng, 24, 864-869 (2011).

8. Hu, T., Lv, X., Bai, C., Lun, Z. \& Qiu, G. Reduction behavior of Panzhihua titanomagnetite concentrates with coal. Metal. Mater. Trans. B, 44B, 252-260 (2013).

9. Sun, H., Dong, X., She, X., Xue, Q. \& Wang, J. Solid State Reduction of Titanomagnetite Concentrate by Graphite. ISIJ Int, 53, 564-569 (2013).

10. Geng, C. et al. Effect of $\mathrm{Na} 2 \mathrm{SO} 4$ on the embedding direct reduction of beach titanomagnetite and the separation of titanium and iron by magnetic separation. ISIJ Int, 55, 2543-2549 (2015).

11. Zhao, W. et al. Investigation of reduction mechanism and kinetics of vanadium titanomagnetite carbon composite hot briquette at 1173-1373 K. Steel Res. Int, 87, 1-9 (2016).

12. Hu, T., Lv, X. \& Bai, C. Enhanced reduction of coal-containing titanomagnetite concentrates briquette with multiple layers in rotary hearth furnace. Steel Res. Int, 87, 494-500 (2016).

13. Gao, E., Sun, T., Liu, Z., Geng, C. \& Xu, C. Effect of sodium sulfate on direct reduction of beach titanomagnetite for separation of iron and titanium. J. Iron. Steel Res. Int, 23, 428-433 (2016).

14. Liu, Y., Zhang, J., Liu, Z. \& Xing, X. Phase transformation behavior of titanium during carbothermic reduction of titanomagnetite ironsand. Int. Journal of Miner. Metal. Mater, 23, 760-768 (2016).

15. Wang, M. et al. Recovery of iron from chromium vanadium-bearing titanomagnetite concentrate by direct reduction. JOM, 68, 2698-2703 (2016). 
16. Zhang, Y. et al. A novel process for the recovery of iron, titanium, and vanadium from vanadiumbearing titanomagnetite: sodium modification-direct reduction coupled process. Int. Journal of Miner. Metal. Mater, 24, 504-511 (2017).

17. Geng, C., Sun, T., Ma, Y., Xu, C. \& Yang, H. Effects of embedding direct reduction followed by magnetic separation on recovering titanium and iron of beach titanomagnetite concentrate. J. Iron. Steel Res. Int, 24, 156-164 (2017).

18. Zhang, Y. et al. A method for recovery of iron, titanium, and vanadium from vanadium-bearing titanomagnetite. Int. Journal of Miner. Metal. Mater, 25, 131-144 (2018).

19. Sarkar, B. K., Kumar, N., Dey, R. \& Das, G. C. Optimization of quenching parameters for the reduction of titaniferous magnetite ore by lean grade coal using the Taguchi method and its isothermal kinetic study. Metal. Mater. Trans. B, 49B, 1822-1833 (2018).

20. Smirnov, K. I., Salikhov, S. P. \& Roshchin, V. E. Solid-phase reduction of iron from Suroyam titanomagnetite ore during metallization in rotary kiln. Mater. Sci. Forum, 946, 512-516 (2019).

21. Zhao, Y., Sun, T., Zhao, H., Chen, C. \& Wang, X. Effect of reductant type on the embedding direct reduction of beach titanomagnetite concentrate. Int. Journal of Miner. Metal. Mater, 26, 152-159 (2019).

22. Zulhan, Z., Adhiwiguna, I. S., Fuadi, A. \& Saleh, N. Solid-state reduction of an Indonesian iron sand concentrate using subbituminous coal. Can. Metall. Q, 60, 12-20 (2021).

23. Zhao, Y., Sun, T. \& Wang, Z. Extraction of iron from refractory titanomagnetite by reduction roasting and magnetic Separation. ISIJ Int, 61, 93-99 (2021).

24. Zulhan, Z. \& Lo, F. Iron nugget formation from iron sand/coal composite pellets under isothermaltemperature gradient profiles. Ironmaking Steelmaking. (2020) https: //doi.org/10.1080/ 03019233.2020 .1859346

\section{Figures}




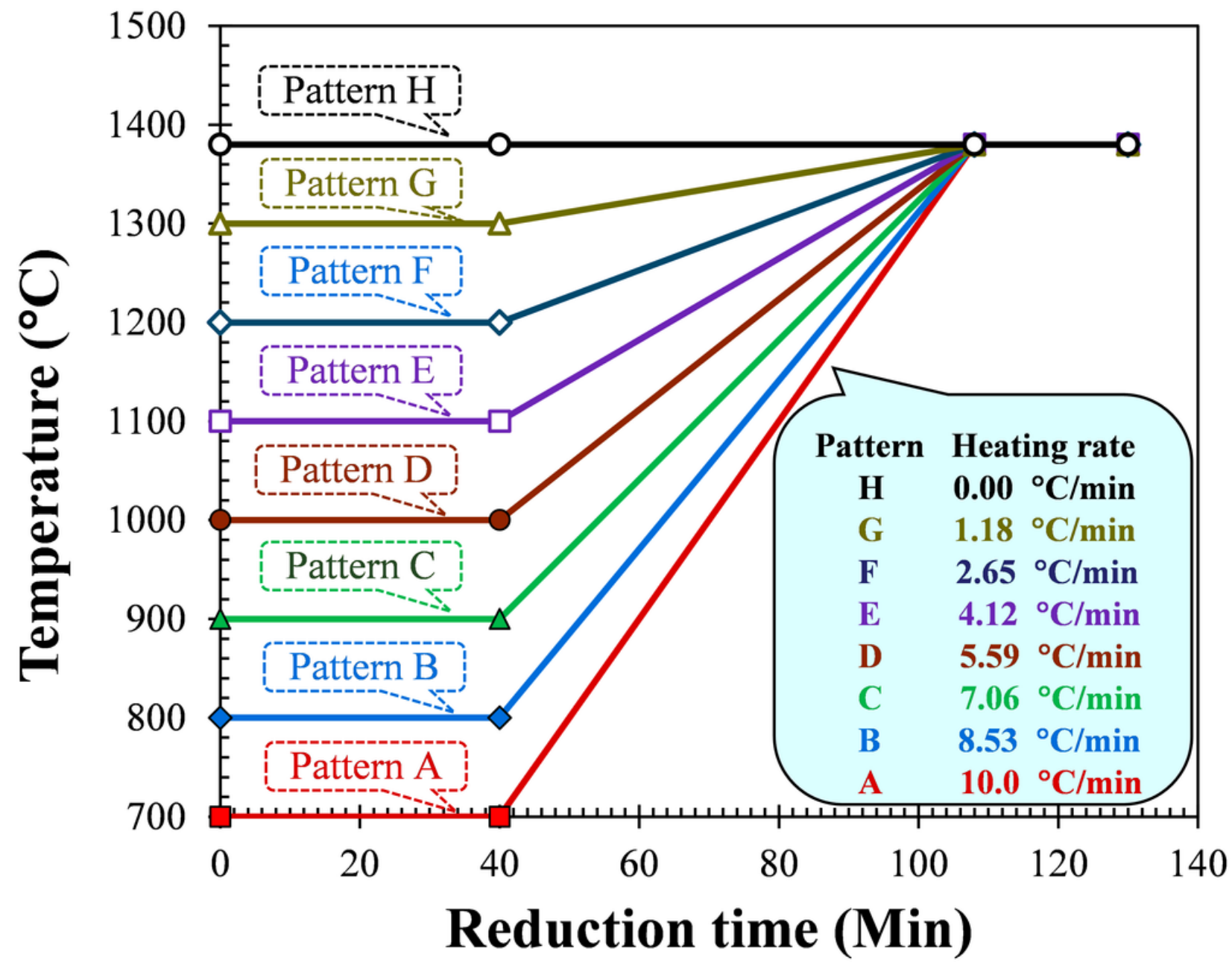

Figure 1

Temperature patterns. 


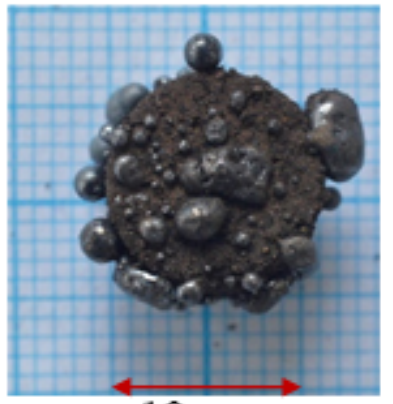

$10 \mathrm{~mm}$

a. Pattern A

$\left(700^{\circ} \mathrm{C}\right)$

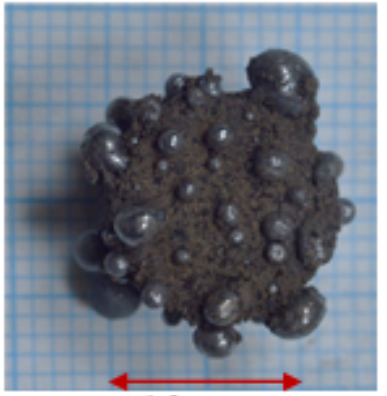

$10 \mathrm{~mm}$

e. Pattern E

$\left(1100^{\circ} \mathrm{C}\right)$

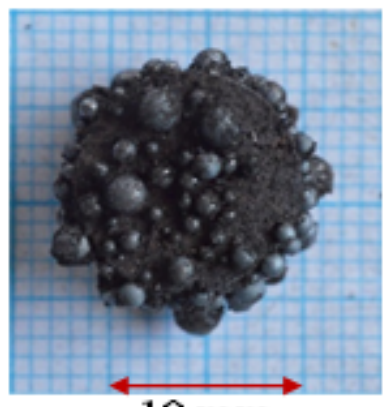

$10 \mathrm{~mm}$

b. Pattern B

$\left(800^{\circ} \mathrm{C}\right)$

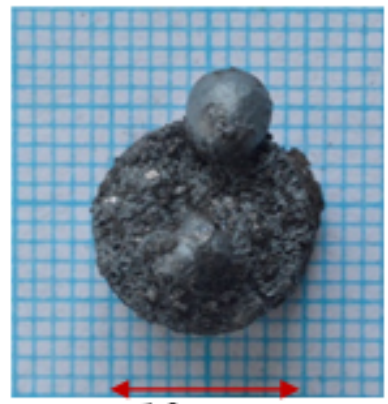

$10 \mathrm{~mm}$

f. Pattern F

$\left(1200^{\circ} \mathrm{C}\right)$

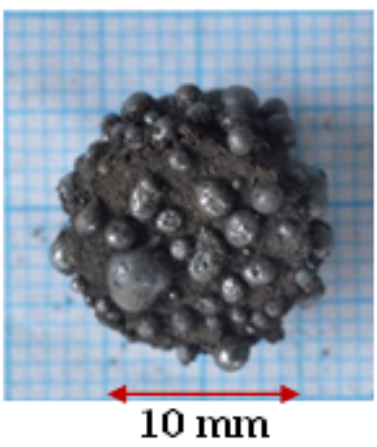

c. Pattern C $\left(900^{\circ} \mathrm{C}\right)$

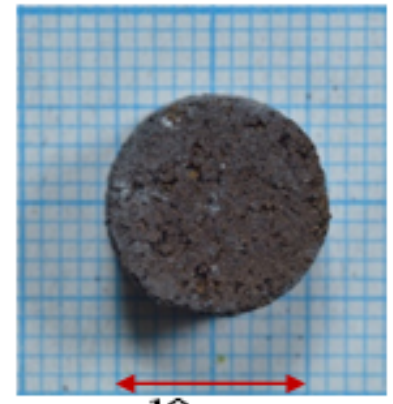

$10 \mathrm{~mm}$

g. Pattern G

$\left(1300^{\circ} \mathrm{C}\right)$

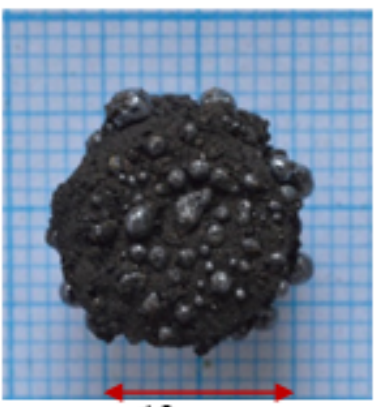

$10 \mathrm{~mm}$

d. Pattern D $\left(1000^{\circ} \mathrm{C}\right)$

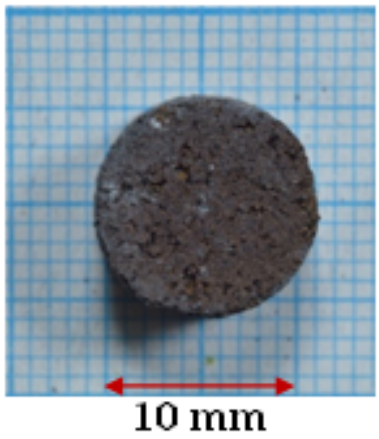

h. Pattern $\mathrm{H}$ $\left(1380^{\circ} \mathrm{C}\right)$

\section{Figure 2}

Reduced briquettes resulting from different temperature patterns.

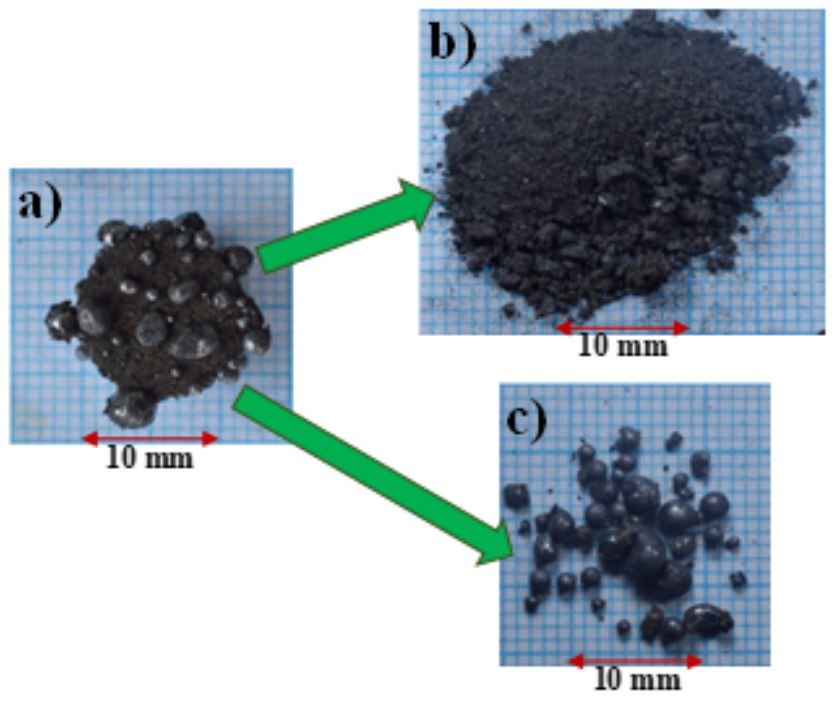

Figure 3

Separation of reduced briquette (a) into slag (b) and iron nuggets (c). 


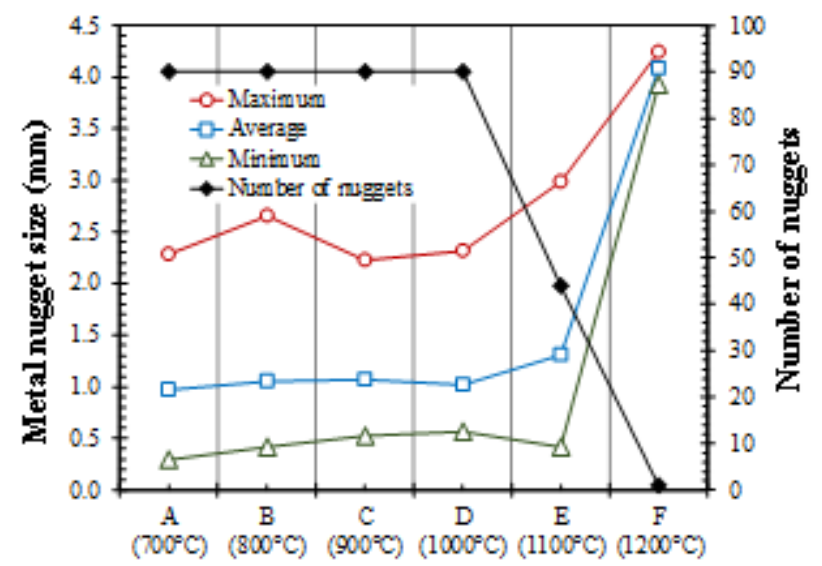

Temperature Pattern

a. Iron nugget size and number (average from two reduced briquettes).

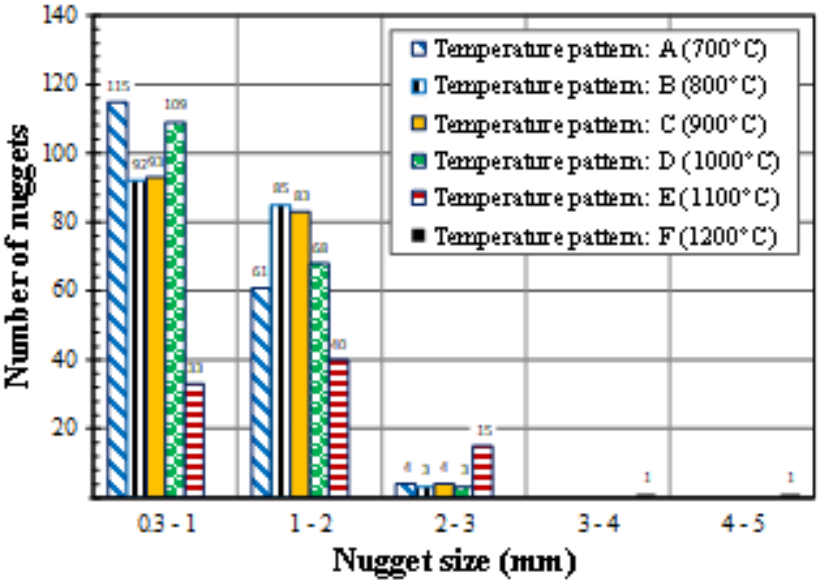

b. Nugget size distribution (total from two reduced briquettes)

Figure 4

Iron nugget size and distribution for different temperature patterns

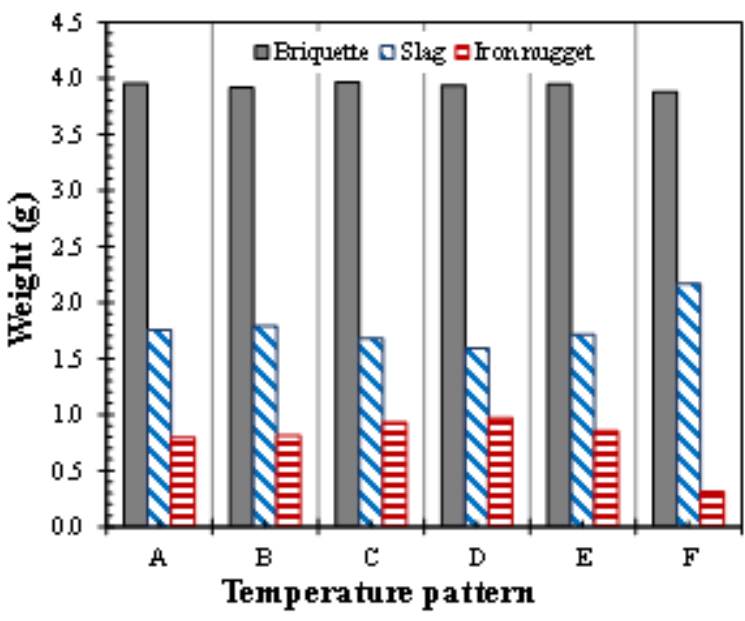

a. Weight of initial briquette, slag, and

\section{nugget}

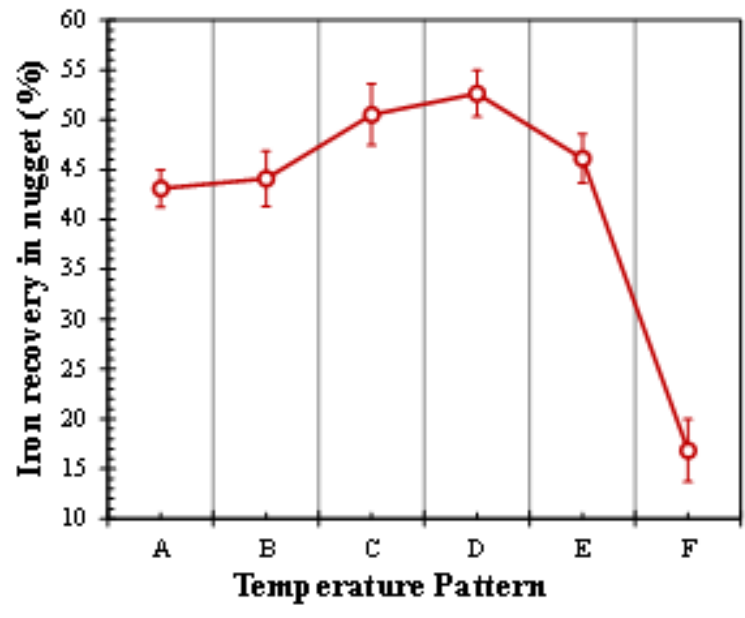

b. Iron recovery

Figure 5

Weight of iron nugget, slag and iron recovery for different temperature patterns. 


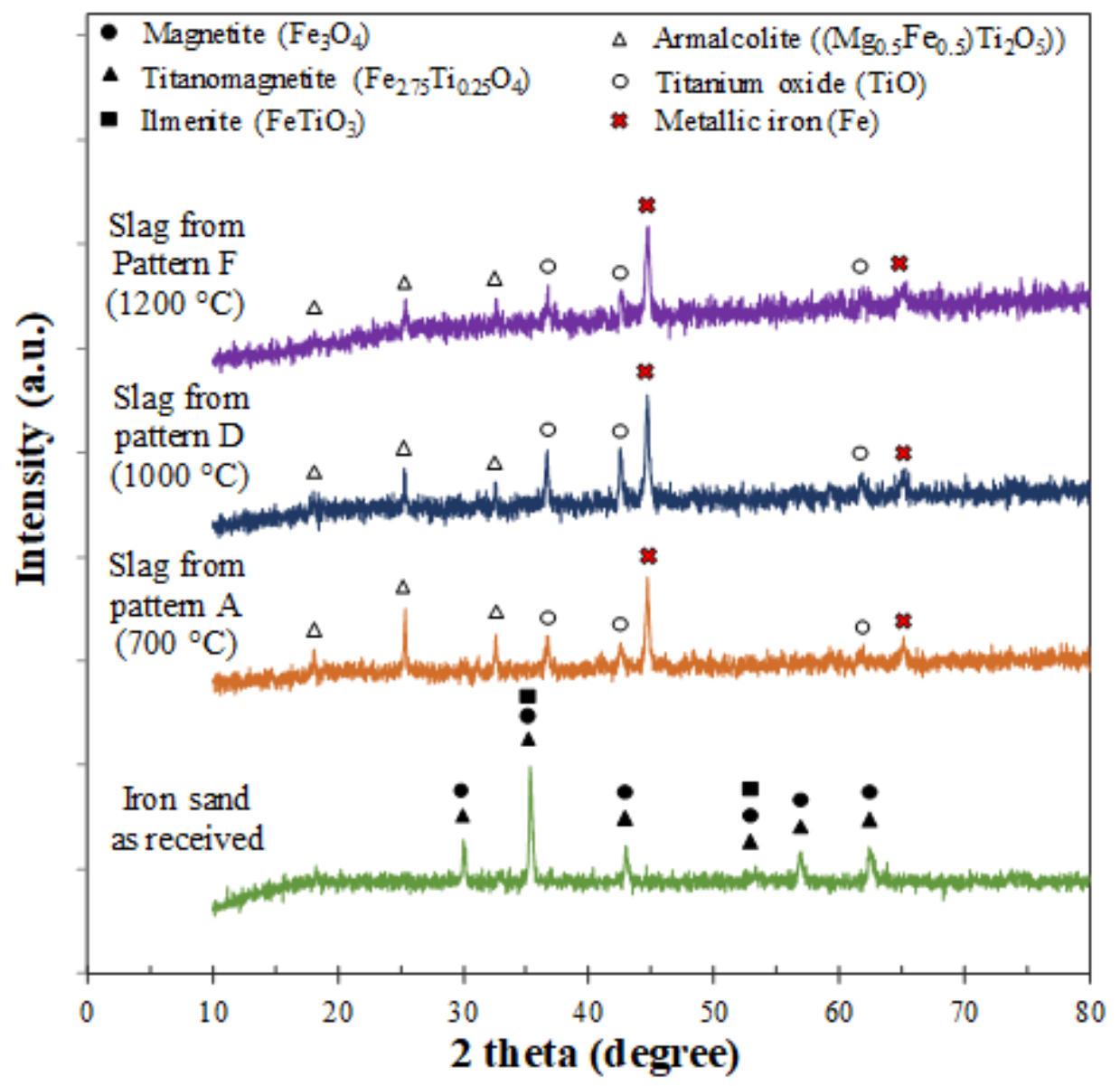

Figure 6

XRD pattern of slag after iron nugget separation. 


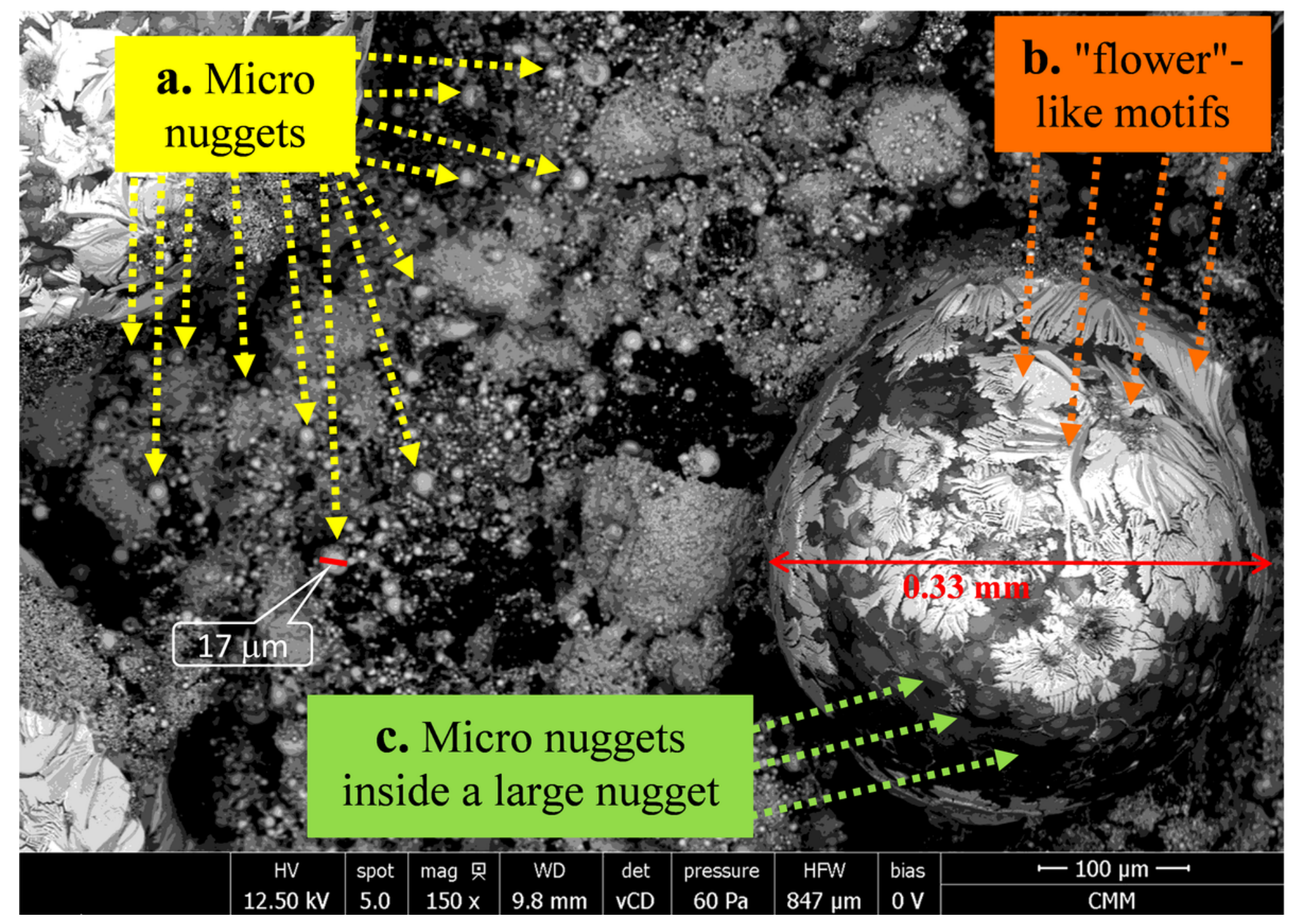

Figure 7

SEM image on the surface of the reduced briquette produced using the temperature pattern $A$. 空

Figure 8

SEM image on the surface of the nugget produced using the temperature pattern A. 


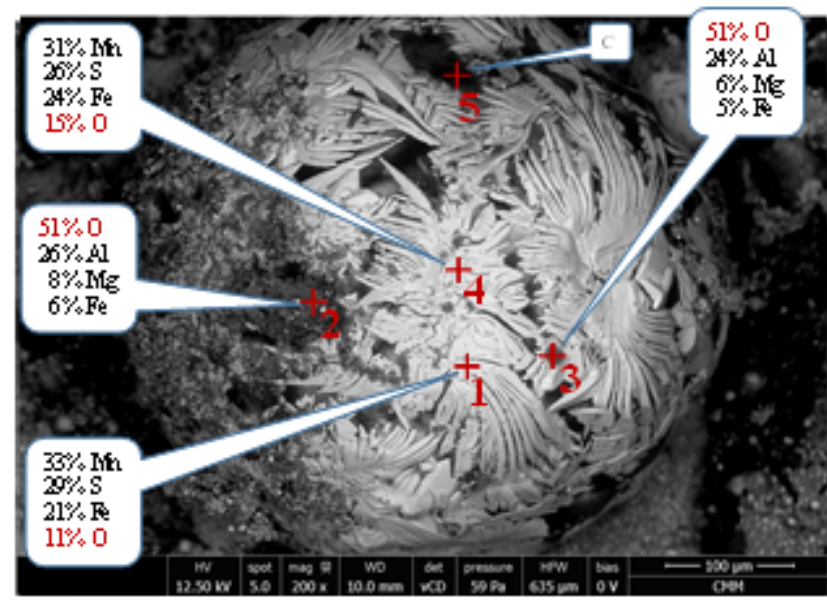

a. Temperature pattern $\mathrm{A}\left(700^{\circ} \mathrm{C}\right)$

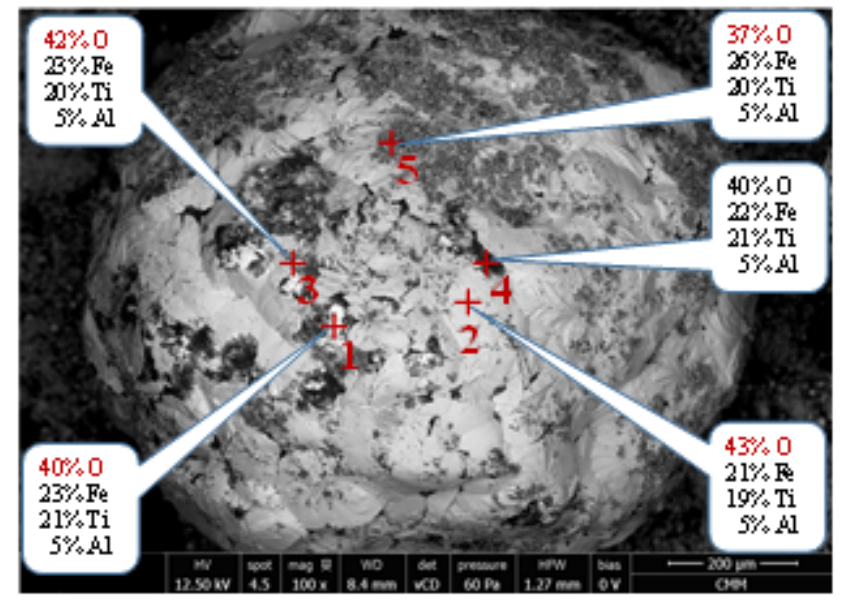

b. Temperature pattern $\mathrm{D}\left(1000^{\circ} \mathrm{C}\right)$

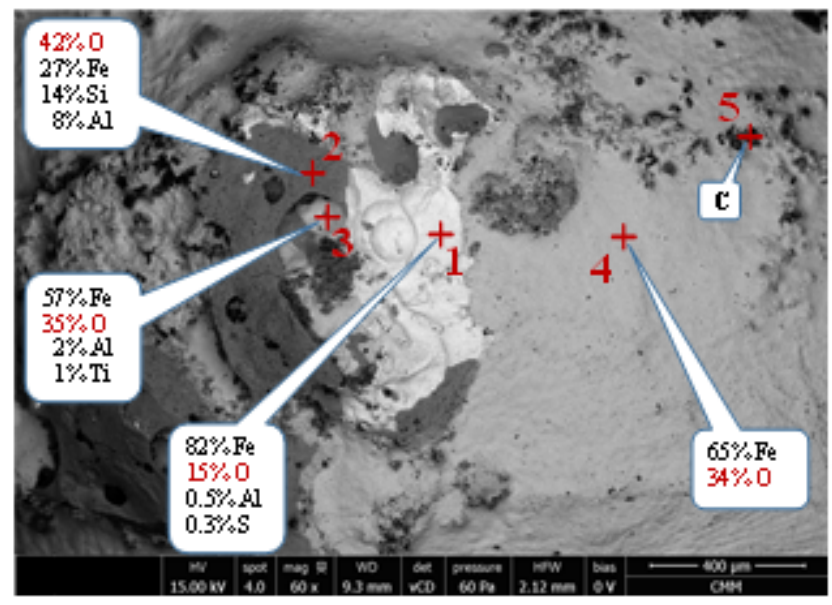

c. Temperature pattern $\mathrm{F}\left(1200^{\circ} \mathrm{C}\right)$

Figure 9

SEM-EDS on the surface of reduced nuggets. 


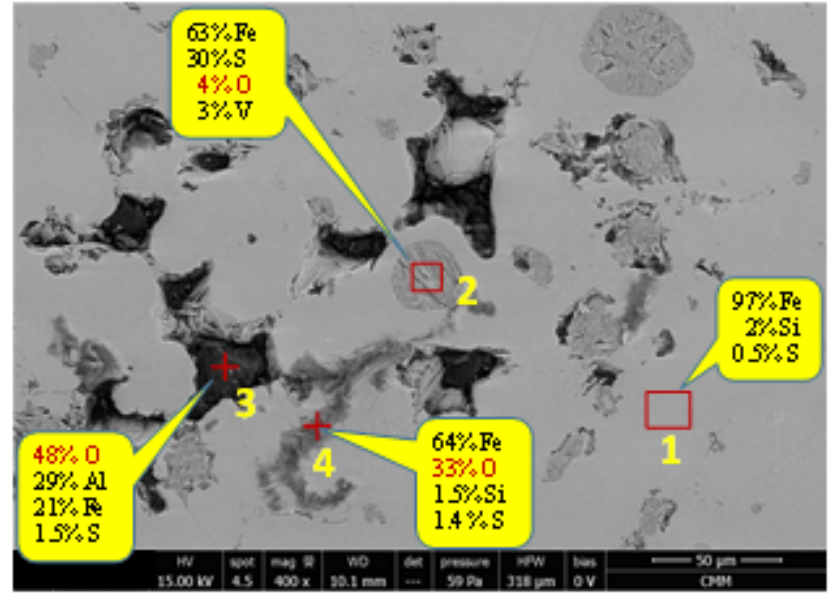

a. Temperature pattern $\mathrm{A}\left(700^{\circ} \mathrm{C}\right)$

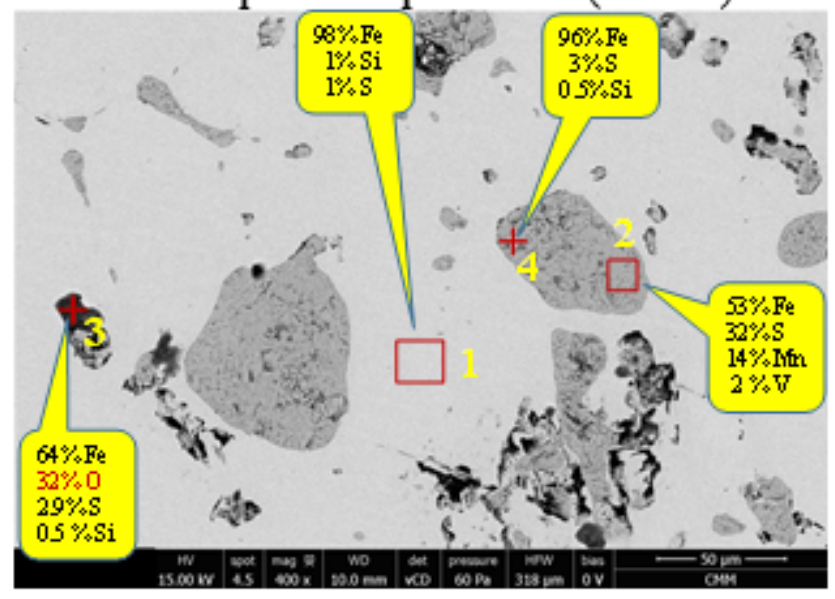

c. Temperature pattern $\mathrm{F}\left(1200^{\circ} \mathrm{C}\right)$

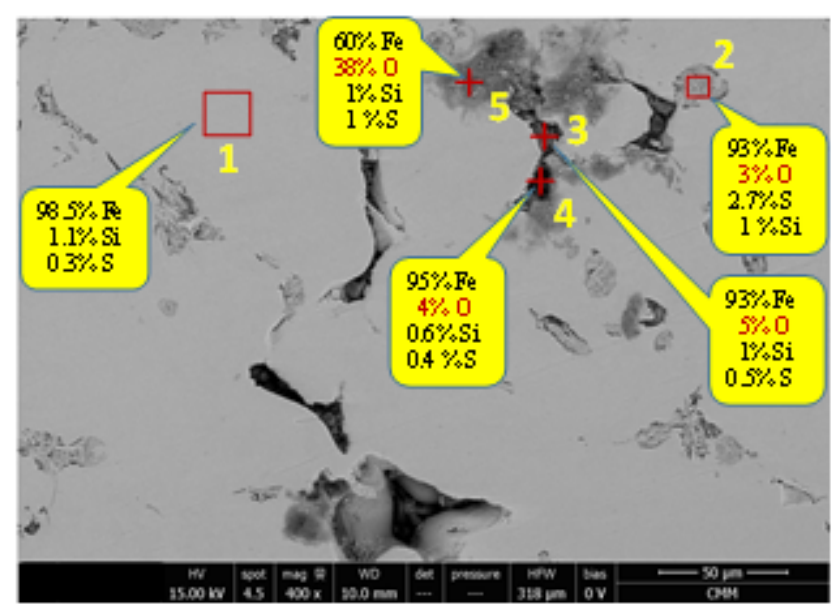

b. Temperature pattern $\mathrm{D}\left(1000^{\circ} \mathrm{C}\right)$

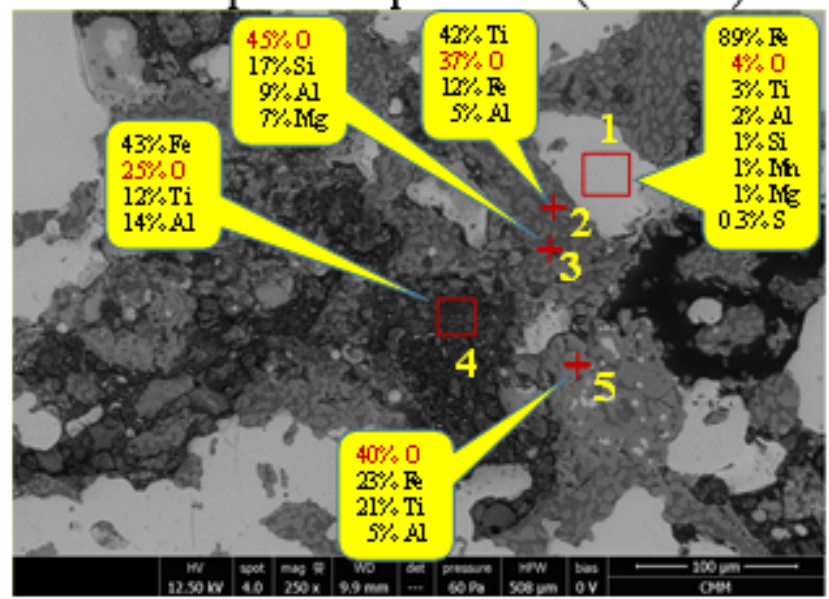

d. Temperature pattern $\mathrm{G}\left(1300^{\circ} \mathrm{C}\right)$

Figure 10

SEM-EDS of the bisection of iron nugget (a-c) and on the polished surface of reduced briquette (d). 


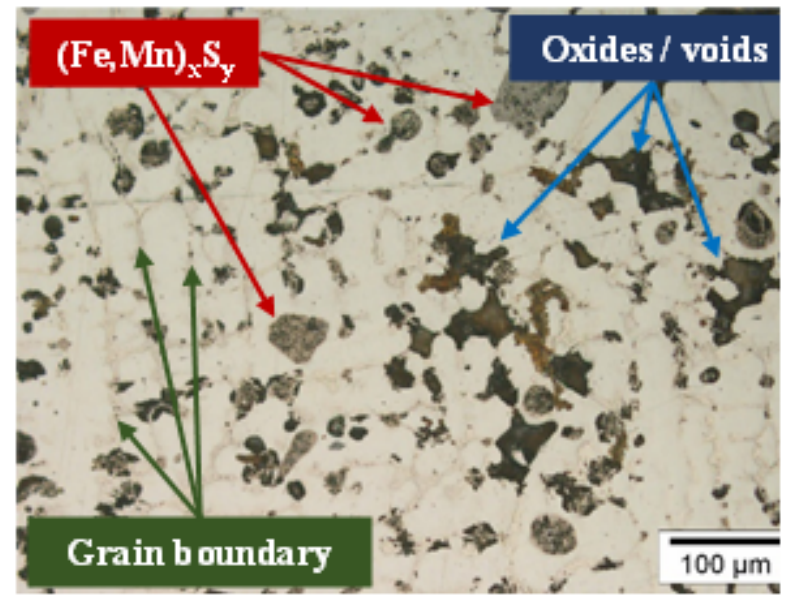

a. Temperature pattern $\mathrm{A}\left(700^{\circ} \mathrm{C}\right), 200 \times$ magnification

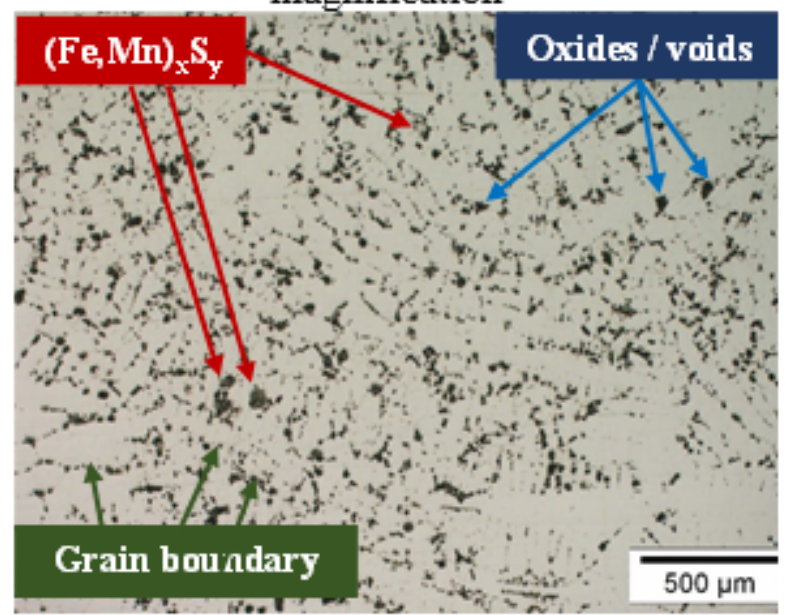

c. Temperature pattern $\mathrm{F}\left(1200^{\circ} \mathrm{C}\right) 50 \times$ magnification

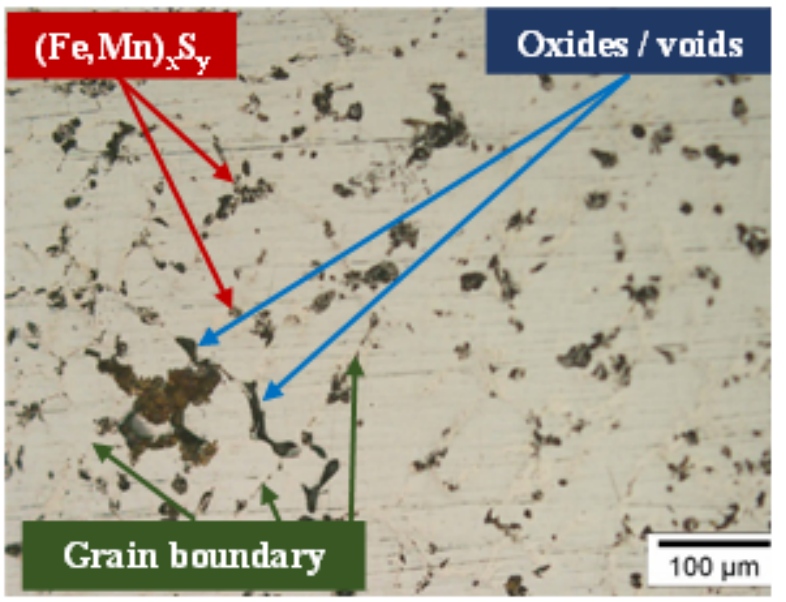

b. Temperature pattern $\mathrm{D}\left(1000^{\circ} \mathrm{C}\right), 200 \times$ magnification

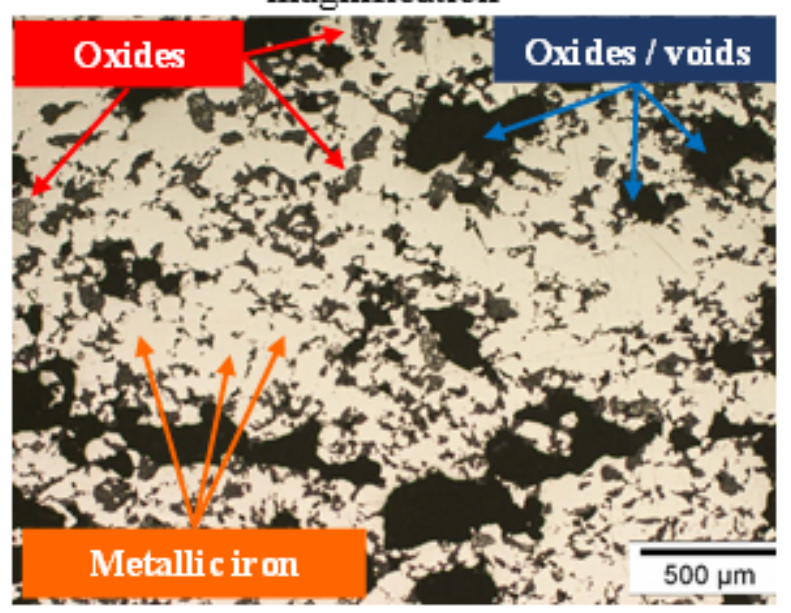

d. Temperature pattern $\mathrm{G}\left(1300^{\circ} \mathrm{C}\right) 50 \times$ magnification

\section{Figure 11}

Optical microscopy image of the bisection of iron nugget (a-c) and polished surface of reduced briquette (d). 